\title{
Tool Wear Classification Using Fuzzy Logic for Machining of Al/SiC Composite Material
}

\author{
V. Kalaichelvi ${ }^{1}$, R. Karthikeyan ${ }^{2}$, D. Sivakumar ${ }^{3}$, V. Srinivasan ${ }^{4}$ \\ ${ }^{1}$ Department of Electronics \& Instrumentation Engineering, BITS-Pilani, Dubai Campus, \\ Dubai, United Arab Emirates \\ ${ }^{2}$ Department of Mechanical Engineering, BITS-Pilani, Dubai Campus, \\ Dubai, United Arab Emirates \\ ${ }^{3}$ Department of Electronics \&Instrumentation Engineering, Annamalai University, Annamalai Nagar, India \\ ${ }^{4}$ Department of Manufacturing Engineering, Annamalai University, Annamalai Nagar, India \\ Email: kalaichelvi@bitsdubai.com
}

Received December 29, 2011; revised February 7, 2012; accepted March 5, 2012

\begin{abstract}
Tool wear state classification has good potential to play a critical role in ensuring the dimensional accuracy of the work piece and prevention of damage to cutting tool in machining process. During machining process, tool wear is an important factor which contributes to the variation of spindle motor current, speed, feed and depth of cut. In the present work, on-line tool wear state detecting method with spindle motor current in turning operation for $\mathrm{Al} / \mathrm{SiC}$ composite material is presented. By analyzing the effects of tool wear as well as the cutting parameters on the current signal, the models on the relationship between the current signals and the cutting parameters are established with partial design taken from experimental data and regression analysis. The fuzzy classification method is used to classify the tool wear states so as to facilitate defective tool replacement at the proper time.
\end{abstract}

Keywords: Tool Wear Classification; Current Signal; Regression Analysis; Fuzzy Classification

\section{Introduction}

The development of an effective means to monitor the wear condition of cutting tools is one of the most important issues in the automation of the cutting process [1]. The consequences of non detection of tool failure may result in a poor quality of product and damage to the work piece or machine [2-4]. Many researchers have looked for ways to detect tool wear states. A large variety of sensors can be used for tool condition sensing. But only a few are reliable and effective. Direct measurement of tool wear using optical methods can be applied only when the tool is not in contact with the workpiece [5].

Indirect methods that rely on the relationship between tool states and measured signals to estimate the tool wear states have been extensively studied. Among the used sensors for monitoring tool condition, motor current sensing constitutes a major method (X. L. Li and S. K. Tso, [6] and Mannan et al., [7] described the feasibility of motor power and motor current sensing for adaptive control and tool condition monitoring. Mannan and Nilsson [8] presented a method using motor current measured from the spindle motor and feed motor to estimate the static torque and thrust in drilling and then to monitor the tool condition. The major advantage of using the measurement of motor current to detect any malfunction in the cutting process is that the measuring apparatus does not disturb the machining process. Moreover it can be applied in the manufacturing environment at almost no extra cost [9].

Most of the indirect approaches have been developed for fixed cutting conditions. In practical applications, however the cutting conditions are not fixed. The spindle speed and feed rate might change according to control strategies. Therefore wear estimation strategy that operates under varying cutting conditions is much needed [10]. A successful monitoring system can effectively maintain machine tools, cutting tool and work piece. Research to date has shown that there are four parameters including cutting force, acoustic emission, motor current and vibration, which could be used to monitor tool, wear condition during turning operation.

Regression is a statistical tool used to find relationship between variables for the purpose of predicting future values. Regression and correlation are introduced as techniques for describing and summarizing data consisting of observation on a dependent or response variable $\mathrm{Y}$ and one or more independent variables. The coefficient of determination $R^{2}$ describes what proportion of total 
variation in observed $\mathrm{Y}$ values can be contributed to this relation [11].

It is very important to develop a reliable and inexpensive intelligent monitoring system for use in cutting processes. A successful monitoring system can effectively maintain machine tools, cutting tools and workpiece [12]. Artificial Neural Network (ANN) can approximate continuous nonlinear functions well, and it is based on the mathematical principles and models of biological neurons and the nervous system. ANN has recently been applied to tool wear monitoring by some researchers. Q. Liu and Y. Altintas [13] have designed Multi-layer feed-forward neural network using force ratio, cutting speed and feed as input variables and flank wear as output response in turning operation. Y. X. Yao et al., [14] have proposed a new method for tool wear detection with different cutting conditions and detected signals which includes the model of wavelet fuzzy neural network with acoustic emission (AE) and the model of fuzzy classification with motor current.

In the present study, the current of the spindle motor is used to estimate the flank wear state. The current depends on the cutting parameters viz, the spindle speed $(v)$, the feed rate $(f)$, and depth of cut $(d)$, as well as its wear $\left(V_{b}\right)$. This paper implements a method for on-line estimation of flank wear from the currents measured using regression technology and a fuzzy classification method over a wide range of cutting conditions. The essence of the method is to establish a simple model relating the measured current value and the flank wear state under different cutting conditions. Based on the model, the tool wear states can then be estimated from the knowledge of the cutting parameters and the motor current signal. According to the tool wear states obtained, the decision about tool replacement can be made.

\section{Experimentation on Metal Cutting Process}

The essence of the method is to establish a simple model relating the measured current value and the flank wear state under different cutting conditions. Experiments are carried out in a Computer Numerical Control (CNC) lathe using K10 cemented carbide tool. The work piece material used for the experiment is LM25 Al (Alumin- ium) $/ 10 \% \mathrm{SiC}_{\mathrm{p}}$ (Silicon Carbide) particulate reinforced composite material prepared through stir casting. The cutting conditions used for experimentation are listed in Table 1.

Cutting tests are performed on a (CNC) Lathe driven by Permanent Magnet Direct Current (PMDC) motor. A PMDC motor is similar to an ordinary DC shunt motor except that its field is provided by permanent magnet instead of salient pole wound field structure. In such motors torque is produced by interaction between the axial current carrying conductors and the magnetic flux produced by the permanent magnets. The DC motor current of the lathe is measured. A personal computer is interfaced with the turning lathe. The cutting conditions are provided as data to the computer and the cutting operation is performed automatically. Figure 1 to Figure 3 show the scanning electron microscopy images of worn out tool in different cutting conditions with varying intensity of wear.

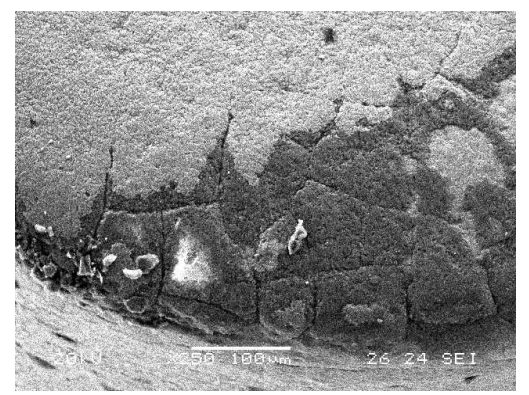

Figure 1. Wear at $v=250 \mathrm{rpm}, f=1.1 \mathrm{~mm} / \mathrm{rev}$ and $d=0.8$ mm.

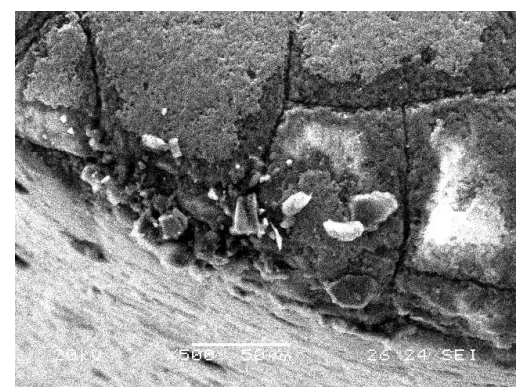

Figure 2. Wear at $v=740 \mathrm{rpm}, f=1.1 \mathrm{~mm} / \mathrm{rev}$ and $d=0.8$ mm.

Table 1. Experimental conditions for metal cutting process.

\begin{tabular}{ccc}
\hline & Spindle speed & $250,740 \mathrm{and} 1150 \mathrm{rpm}$ \\
Cutting conditions & Feed rates & $0.05 \mathrm{and} 1.07 \mathrm{~mm} / \mathrm{rev}$ \\
& Depth of cut & $0.5,0.75 \mathrm{and} 1.0 \mathrm{~mm}$ \\
Work piece & Flank wear & $0.3,0.4,0.5,0.6,0.7,0.8 \mathrm{and} 0.9 \mathrm{~mm}$ \\
Cutting tool & $\mathrm{Al}+10 \%$ of SiC particulate reinforced composite material \\
\hline
\end{tabular}




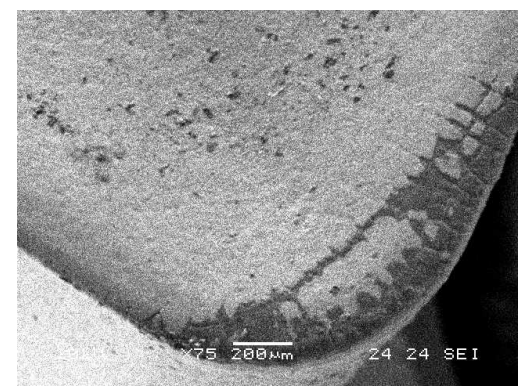

Figure 3. Wear at $v=740 \mathrm{rpm}, f=1.1 \mathrm{~mm} / \mathrm{rev}$ and $d=1$ mm.

Experiments are conducted for various sets of cutting conditions that include spindle speed, feed rate and depth of cut. For each set of cutting conditions, machining is done starting with a fresh tool inserted continuing until the tool worn out A total of 56 tool wear cutting tests are conducted under different cutting conditions, 35 sample data are randomly selected and used as learning samples as shown in Table 2.

The remaining 21 samples are used as the test samples in the classification phase as illustrated in Table 3.

\section{Prediction of Flank Wear Using Regression Analysis and Fuzzy Classification}

Regression analysis is a statistical forecasting model that is concerned with describing and evaluating the relationship between a given variable usually called dependent variable and one or more other variables known as the independent variables. In the present work, a regression method is used to determine the model for the spindle motor current as a function of the spindle speed $v(\mathrm{rpm})$, feed rate $f(\mathrm{~mm} / \mathrm{rev})$ and depth of cut $d(\mathrm{~mm})$. The model was approximately modified so as to describe the flank wear states $w_{i}$ such as $0.30,0.40,0.50,0.60,0.70,0.80$ and $0.90(\mathrm{~mm})$ for $i=1, \cdots, 7$. For different values of cutting conditions the current values are noted experimentally and the corresponding wear values are noted at particular time intervals.

The effect of the cutting variables $v, f$, and $d$ on the current signals, for a sharp tool can be represented by the following equation:

$$
I=K_{0} v^{a 1} f^{a 2} d^{a 3}
$$

where $I$ is the current and $K_{0}$ depends on the tool geometry and work piece material. Taking the logarithmic value of $I$ for differ rent tool wear values, the spindle motor current $S_{i}$ where $i=1, \cdots, 7$ denotes the respective wear values and are given by

$$
\begin{array}{ll}
S_{1}=a_{01}+a_{11} \ln v+a_{21} \ln f+a_{31} \ln d & w_{1}=0.3 \mathrm{~mm}(2) \\
S_{2}=a_{02}+a_{12} \ln v+a_{22} \ln f+a_{32} \ln d & w_{2}=0.4 \mathrm{~mm} \mathrm{(3)}
\end{array}
$$

Table 2. Experimental cutting conditions and current signals.

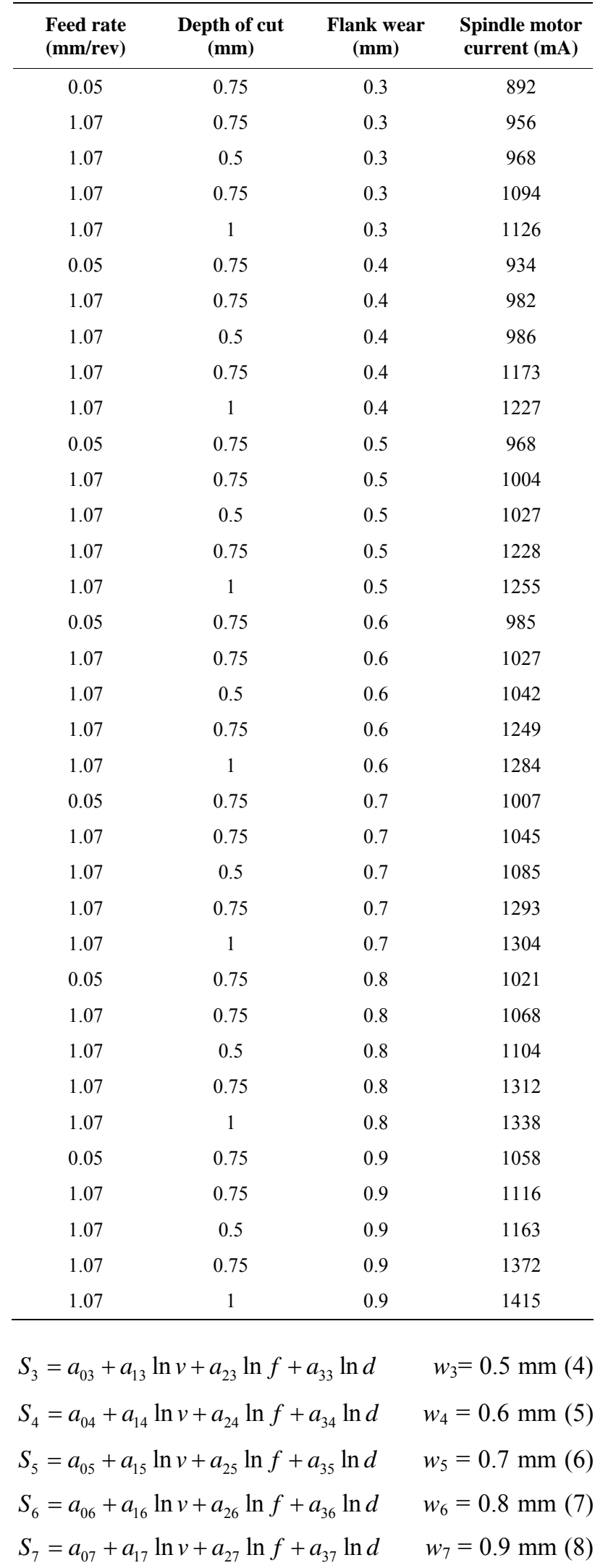


Table 3. Experimental cutting conditions and current signals for test cases.

\begin{tabular}{|c|c|c|c|c|}
\hline $\begin{array}{c}\text { Cutting } \\
\text { speed (rpm) }\end{array}$ & $\begin{array}{l}\text { Feed rate } \\
(\mathrm{mm} / \mathrm{rev})\end{array}$ & $\begin{array}{l}\text { Depth of cut } \\
\text { (mm) }\end{array}$ & $\begin{array}{c}\text { Flank wear } \\
(\mathrm{mm})\end{array}$ & $\begin{array}{l}\text { Spindle motor } \\
\text { current }(\mathrm{mA})\end{array}$ \\
\hline 1150 & 0.05 & 1 & 0.3 & 997 \\
\hline 740 & 1.07 & 0.5 & 0.3 & 968 \\
\hline 250 & 1.07 & 0.75 & 0.3 & 956 \\
\hline 740 & 0.05 & 0.5 & 0.4 & 801 \\
\hline 1150 & 1.07 & 0.75 & 0.4 & 1173 \\
\hline 740 & 1.07 & 1 & 0.4 & 1227 \\
\hline 250 & 0.05 & 0.75 & 0.5 & 814 \\
\hline 740 & 1.07 & 0.5 & 0.5 & 1027 \\
\hline 1150 & 0.05 & 1 & 0.5 & 1123 \\
\hline 740 & 1.07 & 0.75 & 0.6 & 1189 \\
\hline 740 & 0.05 & 0.5 & 0.6 & 846 \\
\hline 1150 & 1.07 & 0.75 & 0.6 & 1249 \\
\hline 250 & 1.07 & 1 & 0.7 & 1136 \\
\hline 740 & 0.05 & 0.75 & 0.7 & 1007 \\
\hline 1150 & 1.07 & 0.75 & 0.7 & 1293 \\
\hline 740 & 0.05 & 0.75 & 0.8 & 1021 \\
\hline 250 & 1.07 & 0.5 & 0.8 & 934 \\
\hline 740 & 1.07 & 0.5 & 0.8 & 1104 \\
\hline 1150 & 0.05 & 1 & 0.9 & 1232 \\
\hline 740 & 1.07 & 0.5 & 0.9 & 1163 \\
\hline 250 & 1.07 & 0.75 & 0.9 & 1116 \\
\hline
\end{tabular}

The actual models derived from the experimental data become

$$
\begin{aligned}
S_{1}= & 511.1558+92.0064 \times \ln v+54.0223 \times \ln f \\
+ & 226.5482 \times \ln d \quad w_{1}=0.3 \mathrm{~mm}, R^{2}=0.995 \\
S_{2}= & 357.9337+127.4543 \times \ln v+61.6012 \times \ln f \\
& +345.6559 \times \ln d \quad w_{2}=0.4 \mathrm{~mm}, R^{2}=0.994 \\
S_{3}= & 287.3501+146.0524 \times \ln v+63.2407 \times \ln f \\
& +392.5424 \times \ln d \quad w_{3}=0.5 \mathrm{~mm}, R^{2}=0.999 \\
S_{4}= & 321.3647+145.1459 \times \ln v+65.0159 \times \ln f \\
& +349.4221 \times \ln d \quad w_{4}=0.6 \mathrm{~mm}, R^{2}=0.999 \\
S_{5}= & 243.7464+160.4426 \times \ln v+68.5357 \times \ln f \\
& +317.7824 \times \ln d \quad w_{5}=0.7 \mathrm{~mm}, R^{2}=0.996 \\
S_{6}= & 278.1798+159.7316 \times \ln v+71.8728 \times \ln f \\
& +337.7303 \times \ln d \quad w_{6}=0.8 \mathrm{~mm}, R^{2}=0.999 \\
S_{7}= & 274.2301+170.8532 \times \ln v+80.5139 \times \ln f \\
& +360.8119 \times \ln d \quad w_{7}=0.9 \mathrm{~mm}, R^{2}=0.993
\end{aligned}
$$

where $R^{2}$ is the correlation coefficient obtained in the regression analysis. It is observed that the correlation coefficients are very close to unity, and the relationship between the current signals and the cutting parameters is reasonably well represented by the proposed models for different tool wear states.

Figure 4 shows the effect of depth of cut on the current signals. It is found that current signal increases as the depth of cut increases, with almost linear relationship. Figure 5 shows the effect of the feed rate on the current signal. Current signal increases as the feed rate increases. The reason for the condition is complex and is discussed by Shaw [15]. Figure 6 shows the main effect of the spindle speed on the current signal. It is found that current signals increases with quadratic relation as the speed in increases. Figure 7 shows the effect of tool wear on the current signals. Spindle motor current increases ex-

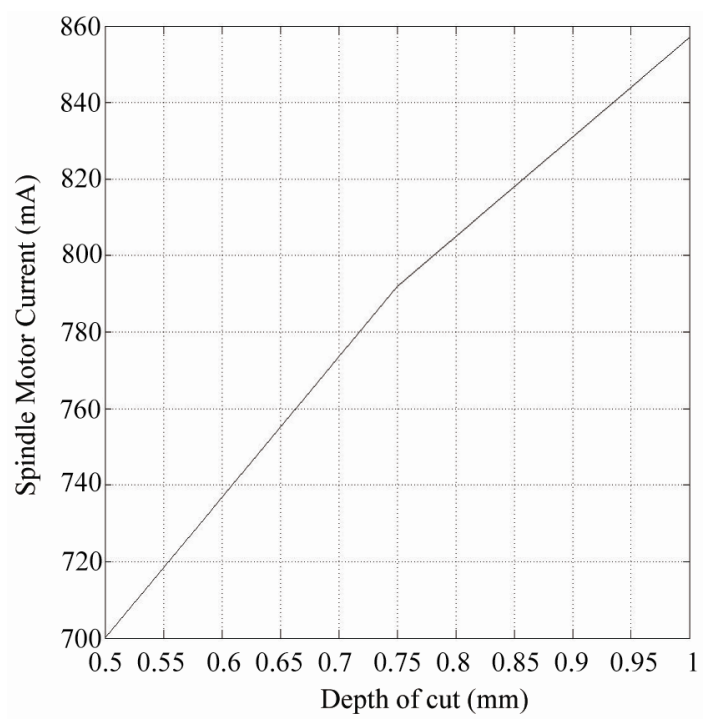

Figure 4. Effect of depth of cut on current signal.

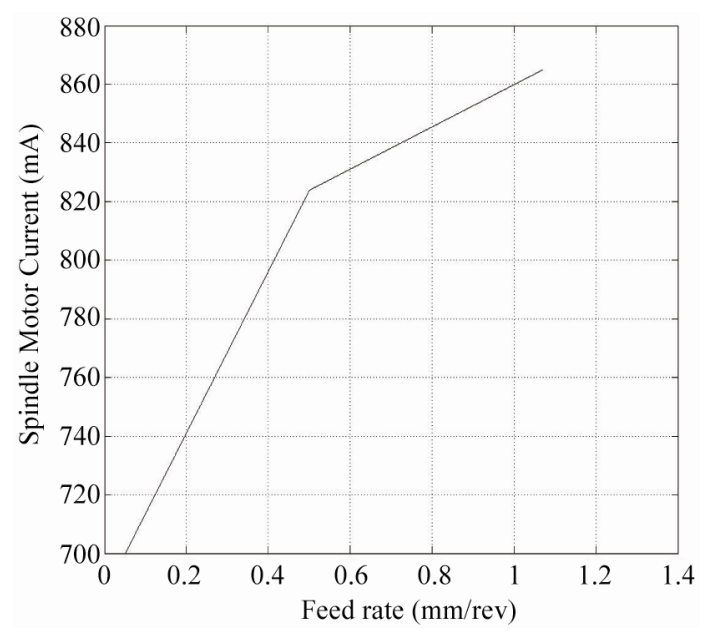

Figure 5. Effect of feed rate on current signal. 


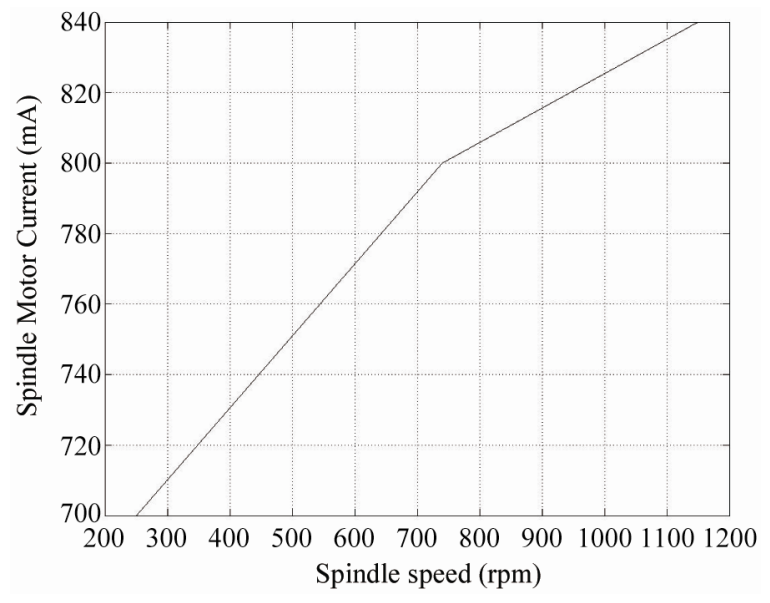

Figure 6. Effect of spindle speed on current signal.

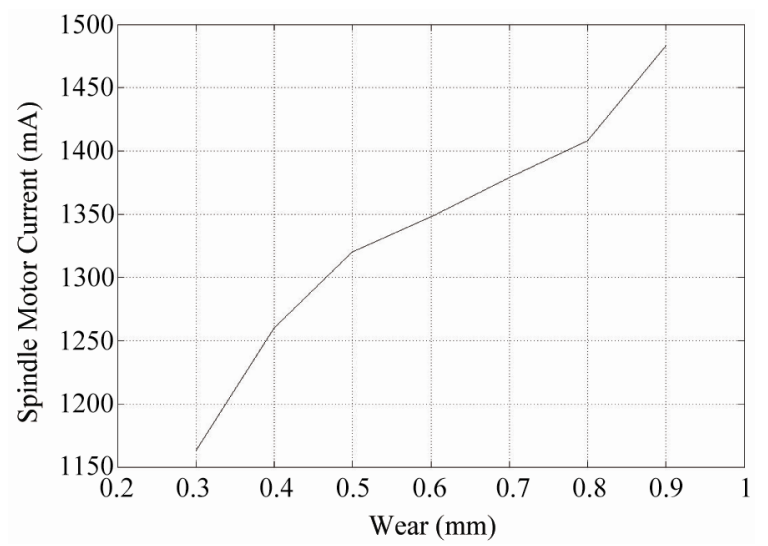

Figure 7. Effect of wear on current signal.

ponentially as tool wear increase with an almost incremental relationship. It is found that the tool wear has more significant effect on the spindle motor current. Based on above studies, it is seen that the tool wear, spindle speed, feed rate, dept of cut and current signals are related. The spindle motor current can be selected as a function of wear states in turning, taking into account the cutting parameters.

It has been recognized widely that the tool life can be divided into three phases characterized by three different wear processes, 1) break in, 2) normal wear and 3) abnormal or catastrophic wear. The sudden rise in the wear rate observed during the abnormal tool wear phase is of interest here as an indication of the need for tool replacement. Because many factors affect tool wear, the tool wear curve usually fluctuates and is not smooth. The current signal models for the different wear states (flank wear $=0.3 \cdots 0.9 \mathrm{~mm}$ ) are established. The models can then be used to estimate the tool wear state from measured current signals, and other cutting parameters. Thirtyfive experimental results were used for the development of regression models (Table 2). Twenty-one additional tests were conducted to examine the feasibility of using these models to estimate the tool wear state as in Table 3. Table 4 shows the comparison of the measured and estimated spindle current using Equations (9)-(15) respectively.

The measured current and estimated currents are defined as real feature values $\left(S_{0}\right)$ and estimated feature values $\left(S_{i}\right)$ (where $i=1, \cdots, 7$ ), respectively. $S_{0}$ values are compared in turn with the estimated feature values for different wear states $(0.3 \cdots 0.9 \mathrm{~mm})$ in order to evaluate the degree of similarity between the real wear state to any of the estimated wear state.

For the spindle motor current, the following membership functions $\mu_{S_{i}}$ are established

1) If $S_{0}<S_{i}(i=1, \cdots, 7)$ then

$$
\begin{aligned}
\mu_{S_{1}}\left(S_{0}\right) & =1 \\
\mu_{S_{2}}\left(S_{0}\right) & =\mu_{S_{3}}\left(S_{0}\right)=\mu_{S_{4}}\left(S_{0}\right)=\mu_{S_{5}}\left(S_{0}\right) \\
& =\mu_{S_{6}}\left(S_{0}\right)=\mu_{S_{7}}\left(S_{0}\right)=0
\end{aligned}
$$

2) If $S_{1} \leq S_{0}<S_{2}$ then

$$
\begin{aligned}
\mu_{S_{1}}\left(S_{0}\right) & =\frac{S_{2}-S_{0}}{S_{2}-S_{1}} \quad \mu_{S_{2}}\left(S_{0}\right)=\frac{S_{0}-S_{1}}{S_{2}-S_{1}} \\
\mu_{S_{3}}\left(S_{0}\right) & =\mu_{S_{4}}\left(S_{0}\right)=\mu_{S_{5}}\left(S_{0}\right)=\mu_{S_{6}}\left(S_{0}\right) \\
& =\mu_{S_{7}}\left(S_{0}\right)=0
\end{aligned}
$$

3) If $S_{2} \leq S_{0}<S_{3}$ then

$\mu_{S_{1}}\left(S_{0}\right)=\mu_{S_{4}}\left(S_{0}\right)=\mu_{S_{5}}\left(S_{0}\right)=\mu_{S_{6}}\left(S_{0}\right)=\mu_{S_{7}}\left(S_{0}\right)=0$

$\mu_{S_{2}}\left(S_{0}\right)=\frac{S_{3}-S_{0}}{S_{3}-S_{2}} \quad \mu_{S_{3}}\left(S_{0}\right)=\frac{S_{0}-S_{2}}{S_{3}-S_{2}}$

4) If $S_{3} \leq S_{0}<S_{4}$ then

$\mu_{S_{1}}\left(S_{0}\right)=\mu_{S_{2}}\left(S_{0}\right)=\mu_{S_{5}}\left(S_{0}\right)=\mu_{S_{6}}\left(S_{0}\right)=\mu_{S_{7}}\left(S_{0}\right)=0$

$\mu_{S_{3}}\left(S_{0}\right)=\frac{S_{4}-S_{0}}{S_{4}-S_{3}} \quad \mu_{S_{4}}\left(S_{0}\right)=\frac{S_{0}-S_{3}}{S_{4}-S_{3}}$

5) If $S_{4} \leq S_{0}<S_{5}$ then

$\mu_{S_{1}}\left(S_{0}\right)=\mu_{S_{2}}\left(S_{0}\right)=\mu_{S_{3}}\left(S_{0}\right)=\mu_{S_{6}}\left(S_{0}\right)=\mu_{S_{7}}\left(S_{0}\right)=0$

$\mu_{S_{4}}\left(S_{0}\right)=\frac{S_{5}-S_{0}}{S_{5}-S_{4}} \quad \mu_{S_{5}}\left(S_{0}\right)=\frac{S_{0}-S_{4}}{S_{5}-S_{4}}$

6) If $S_{5} \leq S_{0}<S_{6}$ then

$\mu_{S_{1}}\left(S_{0}\right)=\mu_{S_{2}}\left(S_{0}\right)=\mu_{S_{3}}\left(S_{0}\right)=\mu_{S_{4}}\left(S_{0}\right)=\mu_{S_{7}}\left(S_{0}\right)=0$

$\mu_{S_{5}}\left(S_{0}\right)=\frac{S_{6}-S_{0}}{S_{6}-S_{5}} \quad \mu_{S_{6}}\left(S_{0}\right)=\frac{S_{0}-S_{5}}{S_{6}-S_{5}}$

7) If $S_{6} \leq S_{0}<S_{7}$ then

$\mu_{S_{1}}\left(S_{0}\right)=\mu_{S_{2}}\left(S_{0}\right)=\mu_{S_{3}}\left(S_{0}\right)=\mu_{S_{4}}\left(S_{0}\right)=\mu_{S_{5}}\left(S_{0}\right)=0$ 
Table 4. Comparison of measured and estimated spindle motor current.

\begin{tabular}{|c|c|c|c|c|c|c|c|c|}
\hline \multirow{2}{*}{ Test } & \multirow{2}{*}{ Measured current $(\mathrm{mA})\left(S_{0}\right)$} & \multicolumn{7}{|c|}{ Estimated current (mA) } \\
\hline & & $\left(S_{1}\right)$ & $\left(S_{2}\right)$ & $\left(S_{3}\right)$ & $\left(S_{4}\right)$ & $\left(S_{5}\right)$ & $\left(S_{6}\right)$ & $\left(S_{7}\right)$ \\
\hline 1 & 997 & 997.7 & 1089.6 & 1127.2 & 1149.5 & 1169.2 & 1188.6 & 1237.1 \\
\hline 2 & 968 & 965.6 & 982.6 & 1028.1 & 1042.5 & 1088.1 & 1104.2 & 1158.3 \\
\hline 3 & 956 & 957.6 & 984.4 & 1003.2 & 1026.7 & 1042.8 & 1067.8 & 1119.2 \\
\hline 4 & 801 & 800.1 & 793.8 & 834.4 & 843.3 & 878.1 & 884.1 & 911.7 \\
\hline 5 & 1173 & 1098.1 & 1178.9 & 1226.1 & 1248.2 & 1287.7 & 1311.6 & 1380.0 \\
\hline 6 & 1227 & 1122.7 & 1222.1 & 1256.5 & 1284.7 & 1308.4 & 1338.3 & 1408.4 \\
\hline 7 & 814 & 792.2 & 795.7 & 809.5 & 827.5 & 832.9 & 847.7 & 872.6 \\
\hline 8 & 1027 & 965.6 & 982.6 & 1028.1 & 1042.5 & 1088.1 & 1104.2 & 1158.3 \\
\hline 9 & 1123 & 997.7 & 1089.6 & 1127.2 & 1149.5 & 1169.2 & 1188.6 & 1237.1 \\
\hline 10 & 1189 & 1057.5 & 1122.7 & 1161.7 & 1184.2 & 1217.0 & 1241.2 & 1304.6 \\
\hline 12 & 1249 & 1098.1 & 1178.9 & 1226.1 & 1248.2 & 1287.7 & 1311.6 & 1380.0 \\
\hline 13 & 1136 & 1022.8 & 1083.8 & 1098.1 & 1127.2 & 1134.3 & 1165.0 & 1223.0 \\
\hline 14 & 1007 & 892.0 & 934.0 & 968.0 & 985.0 & 1007.0 & 1021.0 & 1058.0 \\
\hline 15 & 1293 & 1098.1 & 1178.9 & 1226.1 & 1248.2 & 1287.7 & 1311.6 & 1380.0 \\
\hline 16 & 1021 & 892.0 & 934.0 & 968.0 & 985.0 & 1007.0 & 1021.0 & 1058.0 \\
\hline 17 & 934 & 865.8 & 844.2 & 869.6 & 885.0 & 914.0 & 930.9 & 972.9 \\
\hline 18 & 1104 & 965.6 & 982.6 & 1028.1 & 1042.5 & 1088.1 & 1104.2 & 1158.3 \\
\hline 19 & 1232 & 997.7 & 1089.6 & 1127.2 & 1149.5 & 1169.2 & 1188.6 & 1237.1 \\
\hline 20 & 1163 & 965.6 & 982.6 & 1028.1 & 1042.5 & 1088.1 & 1104.2 & 1158.3 \\
\hline 21 & 1116 & 957.6 & 984.4 & 1003.2 & 1026.7 & 1042.8 & 1067.8 & 1119.2 \\
\hline
\end{tabular}

$$
\mu_{S_{6}}\left(S_{0}\right)=\frac{S_{7}-S_{0}}{S_{7}-S_{6}} \quad \mu_{S_{7}}\left(S_{0}\right)=\frac{S_{0}-S_{6}}{S_{7}-S_{6}}
$$

8) If $S_{0}>S_{i}(i=1, \cdots, 7)$ then

$$
\begin{aligned}
\mu_{S_{1}}\left(S_{0}\right) & =\mu_{S_{2}}\left(S_{0}\right)=\mu_{S_{3}}\left(S_{0}\right)=\mu_{S_{4}}\left(S_{0}\right) \\
& =\mu_{S_{5}}\left(S_{0}\right)=\mu_{S_{6}}\left(S_{0}\right)=0 \\
\mu_{S_{7}}\left(S_{0}\right) & =1
\end{aligned}
$$

where $\mu_{S_{i}}\left(S_{0}\right)$ is the membership degree of current associated with the $i^{\text {th }}$ tool wear state.

The key to the fusion of tool wear states is the selection of appropriate shapes of fuzzy membership function for process variables based on experimental results. Figure 8 shows the trapezoidal membership function of tool wear states. The reason for choosing trapezoidal shape for tool wear states is that it is difficult to quantify an exact wear value.

Using a wider range avoids defining an exact wear value for a certain level of linguistic variable of tool wear. This will also allow an easy knowledge acquisition when developing a set of fuzzy rules for fuzzy inference. Based on the classification of tool wear states, the trapezoidal function is defined as follows [16].

$$
\mu(w)=a w+b, k<w<l
$$

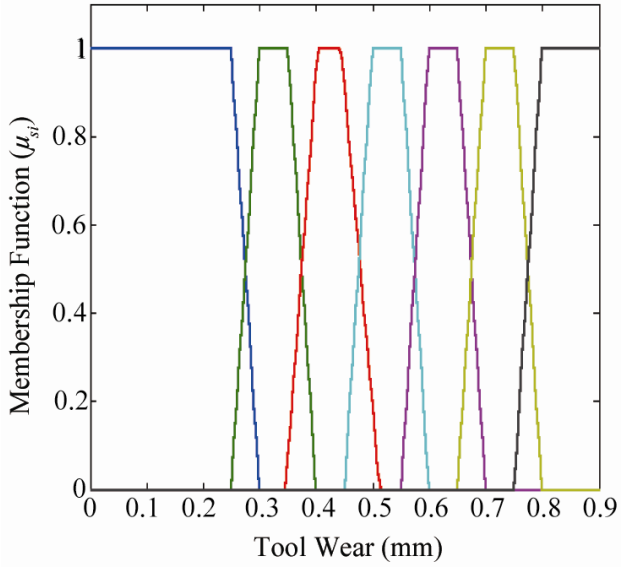

Figure 8. Fuzzy memberships of tool wear state.

where $\mu(w)$ is the fuzzy membership value for tool wear states, and $a, b, k$ and $l$ are constants for different fuzzy sets. The constants of fuzzy membership of tool wear conditions under the A, B, C, D, E, F and G classification are shown in Table 5.

The outputs of the inference are still fuzzy values and they need to be defuzzified. Basically defuzzification is a mapping from a space of fuzzy values into that of the non-fuzzy universe. At present there are several strategies that can be used to perform the defuzzification proc- 
Table 5. Constants of fuzzy membership functions for tool wear condition.

\begin{tabular}{|c|c|c|c|c|}
\hline \multirow{2}{*}{$\begin{array}{l}\text { Tool wear } \\
\text { classification }\end{array}$} & \multicolumn{4}{|c|}{ Constants of fuzzy functions for tool wear condition } \\
\hline & $a$ & B & $\mathbf{K}$ & $I$ \\
\hline \multirow{2}{*}{ A } & 0 & 1 & 0 & 0.25 \\
\hline & -20 & 6 & 0.25 & 0.3 \\
\hline \multirow{3}{*}{ B } & 20 & -5 & 0.25 & 0.3 \\
\hline & 0 & 1 & 0.3 & 0.35 \\
\hline & -20 & 8 & 0.35 & 0.4 \\
\hline \multirow{3}{*}{ C } & 20 & -7 & 0.35 & 0.4 \\
\hline & 0 & 1 & 0.4 & 0.45 \\
\hline & -20 & 10 & 0.45 & 0.5 \\
\hline \multirow{3}{*}{ D } & 20 & -9 & 0.45 & 0.5 \\
\hline & 0 & 1 & 0.5 & 0.55 \\
\hline & -20 & 12 & 0.55 & 0.6 \\
\hline \multirow{3}{*}{$\mathrm{E}$} & 20 & -11 & 0.55 & 0.6 \\
\hline & 0 & 1 & 0.6 & 0.65 \\
\hline & -20 & 14 & 0.65 & 0.7 \\
\hline \multirow{3}{*}{$\mathrm{F}$} & 20 & -13 & 0.65 & 0.7 \\
\hline & 0 & 1 & 0.7 & 0.75 \\
\hline & -20 & 16 & 0.75 & 0.8 \\
\hline \multirow{2}{*}{ G } & 20 & -15 & 0.75 & 0.8 \\
\hline & 0 & 1 & 0.8 & 0.9 \\
\hline
\end{tabular}

ess. The most commonly used method is centroid method of defuzzification which produces the center of area of the possibility distribution of inference output.

Therefore the defuzzified tool wear states can be obtained by using the formula

$$
\text { Wear }=\frac{\int_{w} \mu(w) w d w}{\int_{w} \mu(w) \mathrm{d} w}
$$

where wear represents the numerical value of tool wear states and fuzzy membership degree fused by fuzzy inference.

The membership degree of tool wear state with spindle current $\mu_{S i}(w)$ where $i=\mathrm{A}, \mathrm{B} \cdots \mathrm{G}$ is calculated using fuzzy classification method. The membership degrees of tool wear states are shown in Table 6.

\section{Results and Discussion}

A total of 55 tool wear cutting tests were conducted under various cutting conditions. 35 samples were randomly picked as learning samples and 21 samples were used as the test samples in the classification phase. The above method is used to estimate the tool wear value. The membership degrees of present tool states under different tool wear classification are calculated which is used by fuzzy inference.

Based on studies, it is suggested that the effects of tool

Table 6. Membership degrees of tool wear states (test cases).

\begin{tabular}{|c|c|c|c|c|c|c|c|c|}
\hline \multirow{2}{*}{ Sl. No. } & \multicolumn{7}{|c|}{ Membership degree } & \multirow{2}{*}{$\begin{array}{l}\text { Estimated wear value } \\
\text { (mm) }\end{array}$} \\
\hline & $\mu_{s_{1}}$ & $\mu_{s_{2}}$ & $\mu_{S_{3}}$ & $\mu_{S_{4}}$ & $\mu_{S_{5}}$ & $\mu_{S_{6}}$ & $\mu_{s_{7}}$ & \\
\hline 1 & 1.000 & 0 & 0 & 0 & 0 & 0 & 0 & 0.300 \\
\hline 2 & 0.858 & 0.141 & 0 & 0 & 0 & 0 & 0 & 0.314 \\
\hline 3 & 1.000 & 0 & 0 & 0 & 0 & 0 & 0 & 0.300 \\
\hline 4 & 0 & 0.822 & 0.177 & 0 & 0 & 0 & 0 & 0.417 \\
\hline 5 & 0.073 & 0.927 & 0 & 0 & 0 & 0 & 0 & 0.392 \\
\hline 6 & 0 & 0.857 & 0.142 & 0 & 0 & 0 & 0 & 0.414 \\
\hline 7 & 0 & 0 & 0.750 & 0 & 0 & 0 & 0 & 0.525 \\
\hline 8 & 0 & 0.024 & 0.975 & 0.250 & 0 & 0 & 0 & 0.497 \\
\hline 9 & 0 & 0.111 & 0.888 & 0 & 0 & 0 & 0 & 0.488 \\
\hline 10 & 0 & 0 & 0 & 0 & 0.146 & 0 & 0 & 0.614 \\
\hline 11 & 0 & 0 & 0 & 0.853 & 0.077 & 0 & 0 & 0.607 \\
\hline 12 & 0 & 0 & 0 & 0.922 & 0.020 & 0 & 0 & 0.602 \\
\hline 13 & 0 & 0 & 0 & 0.979 & 0.944 & 0.055 & 0 & 0.705 \\
\hline 14 & 0 & 0 & 0 & 0 & 1.000 & 0 & 0 & 0.700 \\
\hline 15 & 0 & 0 & 0 & 0 & 0.778 & 0.221 & 0 & 0.722 \\
\hline 16 & 0 & 0 & 0 & 0 & 0 & 1.000 & 0 & 0.800 \\
\hline 17 & 0 & 0 & 0 & 0 & 0 & 0.926 & 0.073 & 0.807 \\
\hline 18 & 0 & 0 & 0 & 0 & 0.0124 & 0.987 & 0 & 0.798 \\
\hline 19 & 0 & 0 & 0 & 0 & 0 & 0.105 & 0.894 & 0.889 \\
\hline 20 & 0 & 0 & 0 & 0 & 0 & 0 & 1.000 & 0.900 \\
\hline 21 & 0 & 0 & 0 & 0 & 0 & 0.062 & 0.937 & 0.893 \\
\hline
\end{tabular}


Table 7. Classification of tool wear in turning.

\begin{tabular}{cccccccc}
\hline Classification & A & B & C & D & E & F & G \\
\hline Tool wear value $(\mathrm{mm})$ & $0-0.3$ & $0.25-0.4$ & $0.35-0.5$ & $0.45-0.6$ & $0.55-0.7$ & $0.65-0.8$ & $0.75-0.9$ \\
\hline
\end{tabular}

wear, spindle speed, feed rate and depth of cut should be taken in to account when modeling current signals. In the present work, the tool wear values are divided into $\mathrm{A}, \mathrm{B}$, C, D, E, F \& G classification as shown in Table 7. One of the main objectives of detecting the tool wear state is to obtain a basis for replacing tools. During practical application a noticeable changes of the tool wear states has been examined. According to the estimated tool wear state, a decision can be made if the tool should be replaced. The above method gives the tool wear state according to previously collected data and test results. For turning operation, monitoring can be conducted by calculating the membership grade of the current observation. The tool replacement decision is made when the grade of wear in the current observation exceeds a certain threshold as 0.9. For the present study, the rule for replacement is suggested as follows:

"If the grade of membership $\mu_{S i}$ for the spindle motor current is greater than $0.9 \mathrm{~mm}$ then replace the tool". Figure 9 shows the comparison between measured and predicted values of Tool wear.

\section{Conclusion}

The effects of tool wear and cutting parameters on the spindle motor is analyzed. The model which shows the relationship between the current signals and cutting parameters for different tool wear states (0.3 to 0.9 ) are established through experimental study and regression analysis. The membership function concept has been successfully used to calculate the grade of membership for given wear states and applied to the monitoring of tool wear state. The grade of membership associated with

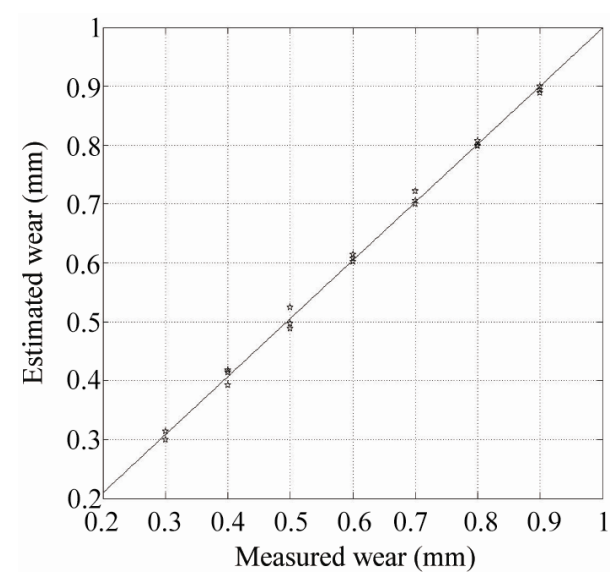

Figure 9. Comparison between measured and predicted values of tool wear using fuzzy classification method. the relevant flank wear is always very close to unity based on the established models. This indicates that the method is acceptable. The control of tool replacement requires the recognition of the tool wear state associated with the cutting parameter including spindle speed and feed rate, which may change according to the control strategies. The use of the grades of membership for the tool wear state provides a scientific basis for controlling the tool replacement. The method is applicable to the choice of any desired threshold of wear according to the quality standard adopted.

\section{REFERENCES}

[1] X. Li, S. Dong and P. K. Venuvinod, "Hybrid Learning for Tool Wear Monitoring," International Journal of Advanced Manufacturing Technology, Vol. 16, No. 5, 2000, pp. 303-307. doi:10.1007/s001700050161

[2] L. C. Lee, K. S. Lee and C. S. Gan, "On the Correlation between Dynamic Cutting Force and Tool Wear," International Journal of Machine Tools and Manufacture, Vol. 29, No. 3, 1989, pp. 295-303.

doi:10.1016/0890-6955(89)90001-1

[3] S. B. Rao, "Metal Cutting Machine Tool Design-A Review," Journal of Manufacturing Science and Engineering Transactions of ASME, Vol. 119, No. 4, 1997, pp. 713-716. doi: $10.1115 / 1.2836814$

[4] K. Danai and A. G. Ulsoy, "Dynamic State Model for On-Line Tool Wear Estimation in Turning," Journal of Engineering for Industry, Transactions of ASME, Vol. 109, No. 4, 1987, pp. 396-399. doi:10.1115/1.3187145

[5] L. Dan and J. Mathew, "Tool Wear and Failure Monitoring Techniques for Turning-A Review," International Journal of Machine Tools and Manufacture, Vol. 30, No. 4, 1990, pp. 579-598. doi:10.1016/0890-6955(90)90009-8

[6] X. L. Li and S. K. Tso, "Drill Wear Monitoring Based on Current Signals," Wear, Vol. 231, No. 2, 1999, pp. 172178. doi:10.1016/S0043-1648(99)00130-1

[7] M. A. Mannan, S. Broms and B. Lindstrom, "Monitoring and Adaptive Control of Cutting Process by Means of Motor Power and Current Measurements," CIRP Annals-Manufacturing Technology, Vol. 38, No. 1, 1989, pp. 347-350. doi:10.1016/S0007-8506(07)62720-6

[8] M. A. Mannan and T. Nilsson, "The Behavior of Static Torque and Thrust Due to Tool Wear in Drilling," Technical Papers of the North American Manufacturing Research Institution of ASME, 1997, pp. 75-80.

[9] G. Byrne, D. Dornfeld, I. Inasaki, G. Ketteler, W. Konig and R. Teti, "Tool Condition Monitoring (TCM)-The Status of Research and Industrial Application," CIRP Annals-Manufacturing Technology, Vol. 44, No. 2, 1995, pp. 541-567. doi:10.1016/S0007-8506(07)60503-4 
[10] Y. Koren, T. Ko and A. G. Ulsoy, "Flank Wear Estimation under Varying Cutting Conditions," Journal of Dynamic Systems, Measurement and Control, Vol. 113, No. 2, 1991, pp. 300-307.

[11] J. L. Devore and N. R. Farnum, “Applied Statistics for Engineers and Scientists," 2nd Edition, Duxbury Press, Belmont, 2004.

[12] J. S. R. Jang, "Adaptive Network Based Fuzzy Inference Systems," IEEE Transactions on Systems, Man and Cybernetics, Vol. 23, No. 3, 1999, pp. 665-685.

[13] Q. Liu and Y. Altintas, "On-Line Monitoring of Flank Wear in Turning with Multilayered Feed-Forward Neural Network," International Journal of Machine Tools and
Manufacture, Vol. 39, No. 12, 1999, pp. 1945-1959. doi:10.1016/S0890-6955(99)00020-6

[14] Y. X. Yao, X. L. Li and Z. J. Yuan, "Tool Wear Detection with Fuzzy Classification and Wavelet Fuzzy Neural Network," International Journal of Machine Tools and Manufacture, Vol. 39, No. 10, 1999, pp. 1525-1538. doi:10.1016/S0890-6955(99)00018-8

[15] M. C. Shaw, "Metal Cutting Principles," Clarendon Press, Oxford, 1984.

[16] X. L. Li, "Real Time Tool Condition Monitoring in Turning," International Journal of Production Research, Vol. 30, No. 5, 2001, pp. 981-992. 